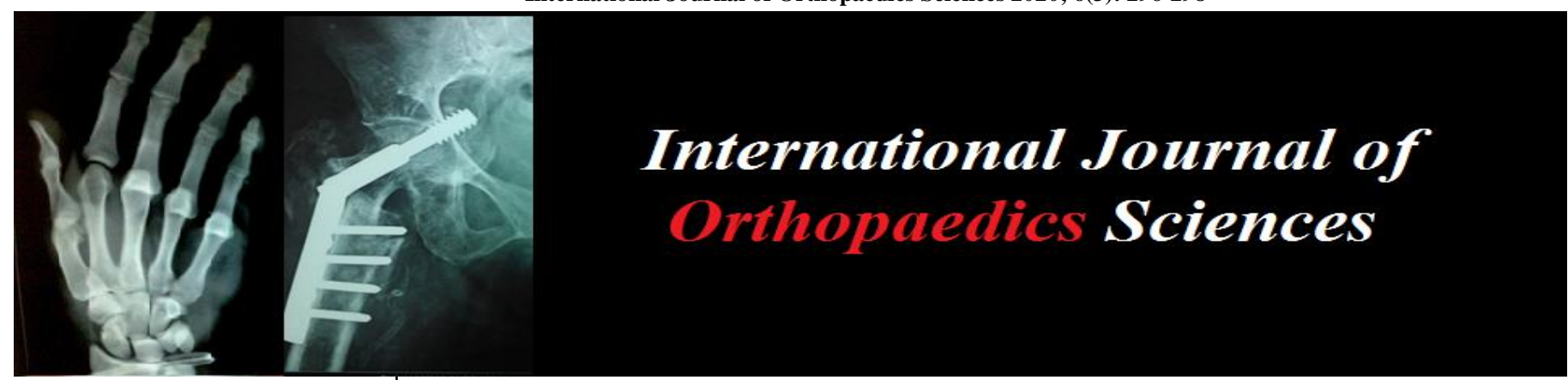

E-ISSN: 2395-1958

P-ISSN: 2706-6630

IJOS 2020; 6(3): 296-298

(C) $2020 \mathrm{IJOS}$

www.orthopaper.com

Received: 27-05-2020

Accepted: 28-06-2020

Sujitkumar Vakati R

Associate Professor, Department

of Orthopaedics, Mamatha

Academy of Medical Sciences

Hospital, Hyderabad,

Telangana, India

Ravindranath VS

Professor, Department of

Orthopaedics, Department of

Orthopaedics, Mamatha

Academy of Medical Sciences

hospital, Hyderabad, Telangana,

India

Srikanth Eppakayala

Senior Resident, Department of

Orthopaedics, Mamatha

Academy of Medical Sciences

Hospital, Hyderabad,

Telangana, India

Sahetya Mohan Rao V

Assistant Professor, Department

of Orthopaedics, Mamatha

Academy of Medical Sciences

Hospital, Hyderabad,

Telangana, India

Naresh Lalam

Post Graduate Department of Orthopaedics, Mamatha medical College and General Hospital,

Khammam, Telangana, India

Corresponding Author: Sujitkumar Vakati R

Associate Professor, Department

of Orthopaedics, Mamatha

Academy of Medical Sciences

Hospital, Hyderabad,

Telangana, India

\section{Avascular necrosis of femoral head: A rare complication of corticosteroid therapy for pemphigus vulgaris}

\author{
Sujitkumar Vakati R, Ravindranath VS, Srikanth Eppakayala, Sahetya \\ Mohan Rao V and Naresh Lalam
}

DOI: $\underline{\text { https://doi.org/10.22271/ortho.2020.v6.i3e.2215 }}$

\section{Abstract}

The avascular necrosis of femoral head is a disease with many etiological factors which affects young population and if not managed timely, leads to collapse of femoral head leading to Secondary Osteoarthritis of the Hip joint. In a pemphigus vulgaris case who is on corticosteroid therapy, developing avascular necrosis is a rare finding. Here in, we report a case of pemphigus vulgaris developing corticosteroid induced avascular necrosis of femoral head.

Keywords: Avascular necrosis, corticosteroid therapy, pemphigus vulgaris

\section{Introduction}

Corticosteroid therapy, irrespective of the mode of administration, has its own attendant risk of side effects. Avascular necrosis of the femoral head is one of the universally recognized side effects of steroid therapy ${ }^{[1]}$. Pietrogrande and Mastomarino reported the first case of avascular necrosis ${ }^{[2]}$. It is mostly seen after intake of large amount of steroid for protracted period ${ }^{[3]}$. The aetiology of avascular necrosis is multifactorial and ranges from traumatic causes namely fracture intracapsular neck of femur, traumatic dislocation of hip, slipped femoral capital epiphysis, and, to nontraumatic causes such as sickle cell anaemia, alcoholism, autoimmune connective tissue disorders as well as pancreatitis, occlusive vascular disease, pheocromocytoma, infections, radiation, Gaucher's disease, renal transplantation, Caisson's disease and pregnancy ${ }^{[4,5,6,7,8,9,10]}$.

Wang et al. proposed three mechanisms by which steroid causes avascular necrosis: (i) Steroid induced hypercoagulable state leading on to embolization. (ii) Osteoporosis with trabecular fractures and collapse. (iii) Steroid induced fatty liver with consequent hyperlipidaemia, fat microemboli and bone infarction, is the most important mechanism ${ }^{[11]}$.

Literature of corticosteroid induced avascular necrosis of femoral head in patients of pemphigus vulgaris are rare. Here, we report avascular necrosis of bilateral femoral head in a young adult male patient of pemphigus vulgaris who was on corticosteroid therapy.

\section{Case report}

A male patient of age 36 years came with chief complaint of bilateral hip joint pain with right side comparatively more than left hip joint since six months. He was unable to do his routine activities. He had associated skin lesions grossly present all over the body except genital area. $\mathrm{He}$ is a known case of pemphigus vulgaris since three years which was confirmed by skin biopsy and direct immunoflourescence. He had been treated by a dermatologist and was on corticosteroid therapy for about two years. Since, six months he developed hip joint pain. There was no history of any fever, cough, shortness of breath, burning micturation, loss of sensation, vomiting, blood in stools and hematuria. He was a known alchoholic for ten years and guthka chewing but has stopped these habits since six months.

On examination, skin lesions were present all over the body. Tenderness was present at both hip joints. Gross limitation of movements of both hip joints (right > left). 
$\mathrm{X}$-ray was taken for hip joints and it showed narrowing of joint space with subchondral sclerosis and early osteoarthritis changes were observed (fig 1).

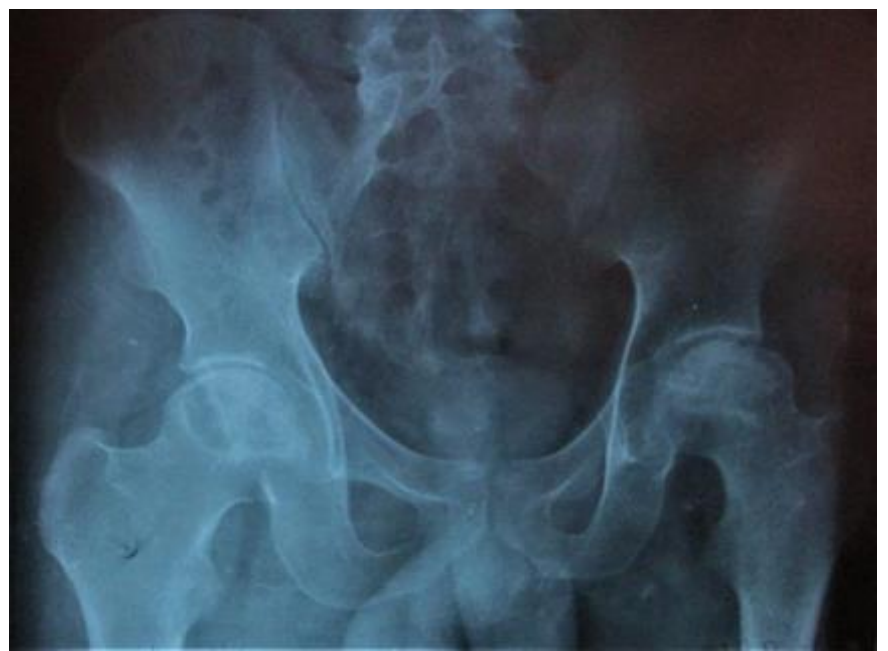

Fig 1: X-ray was taken for hip joints and it showed narrowing of joint space with subchondral sclerosis and early osteoarthritis changes were observed

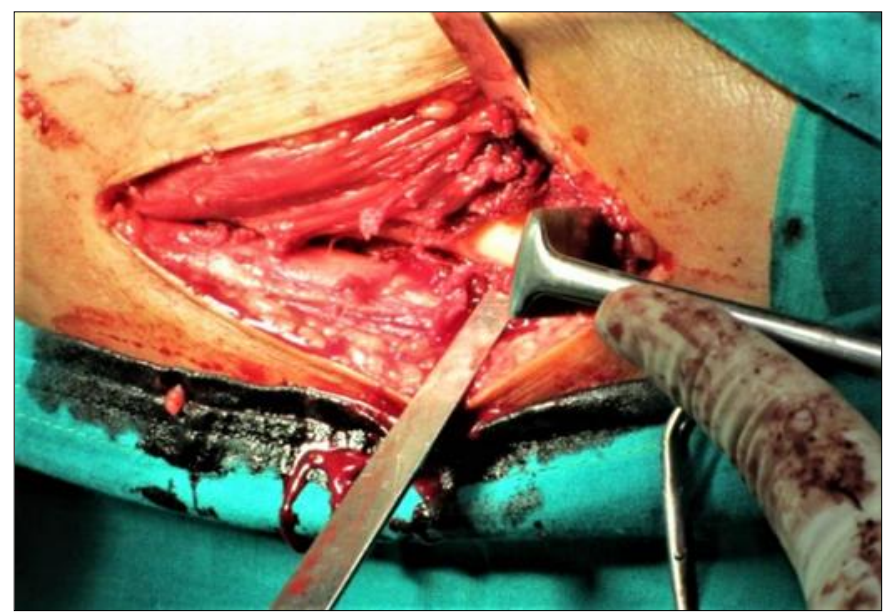

Fig 2: Intraoperatively, proximal femur is exposed by lateral approach

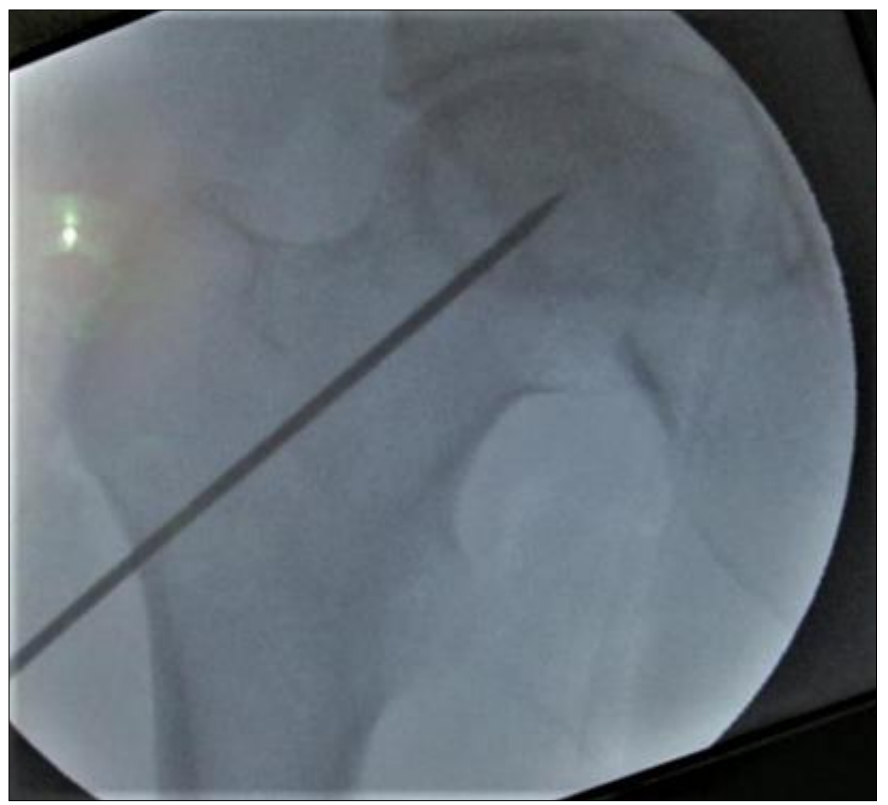

Fig 3: Entry hole made and guide wire passed under c-arm assistance.

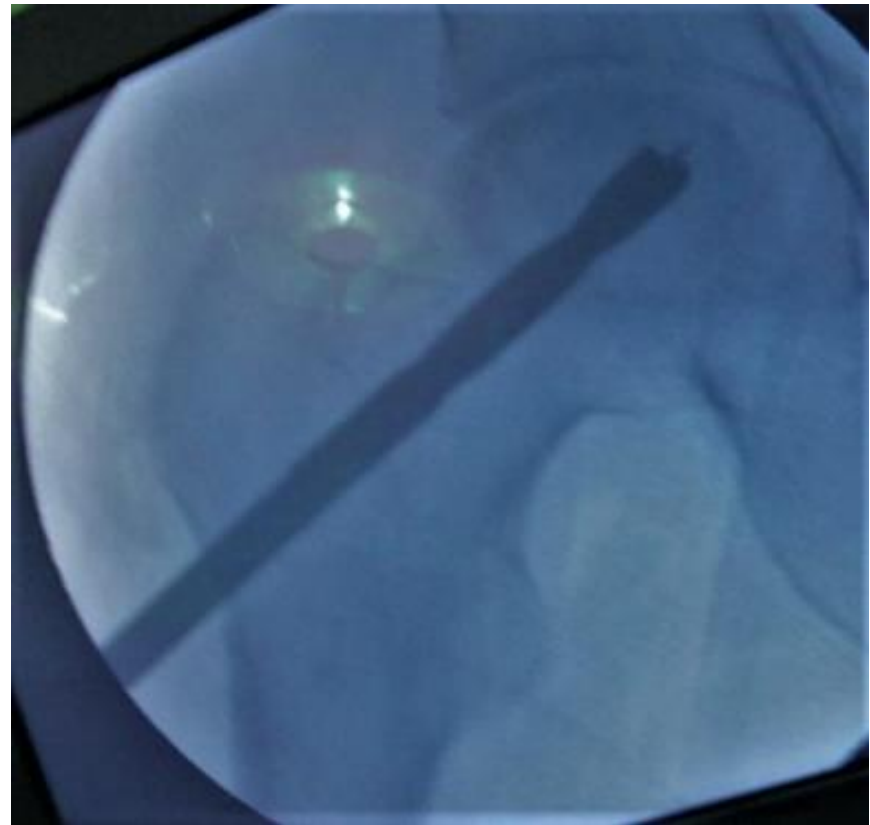

Fig 4: Reaming done over guide wire with DHS reamer

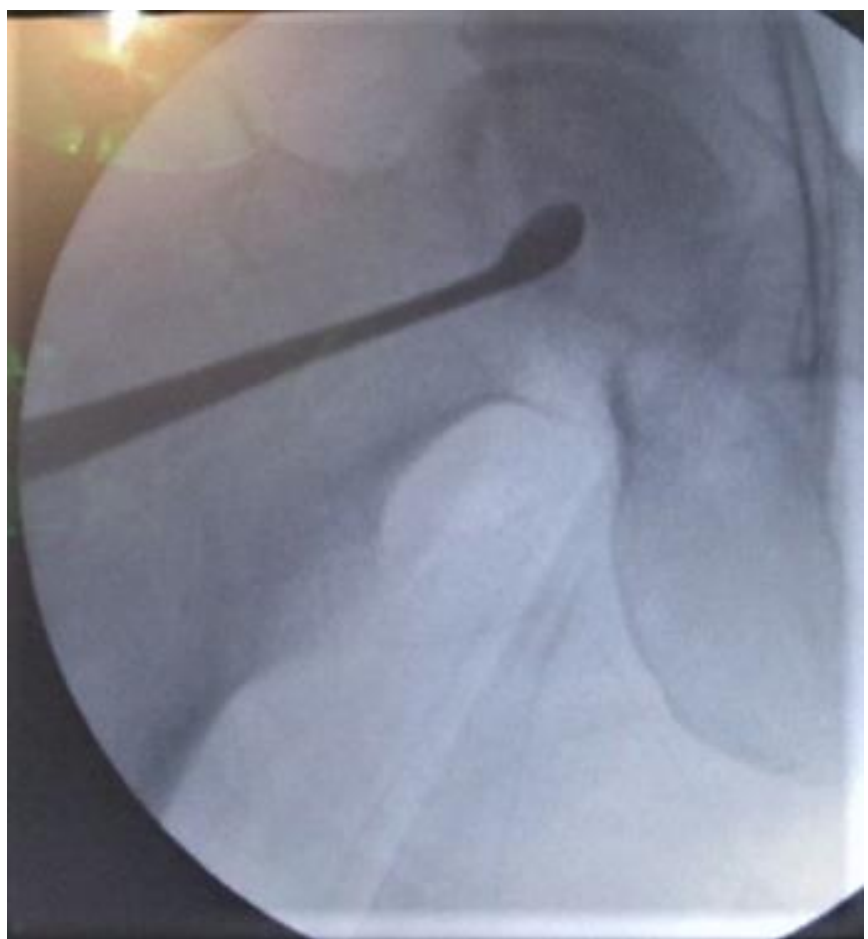

Fig 5: Necrotic material in femur head debrided

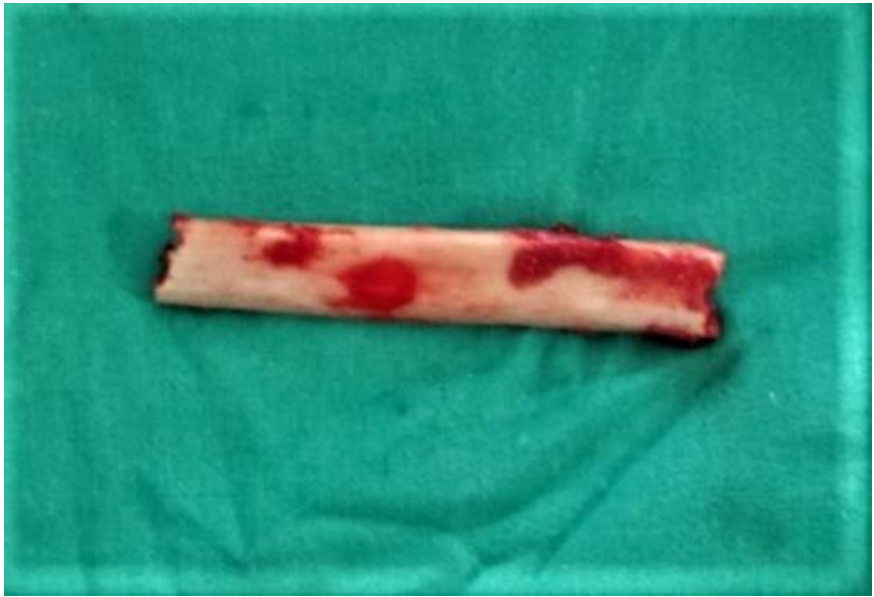

Fig 6: Ipsilateral fibular strut graft harvested 


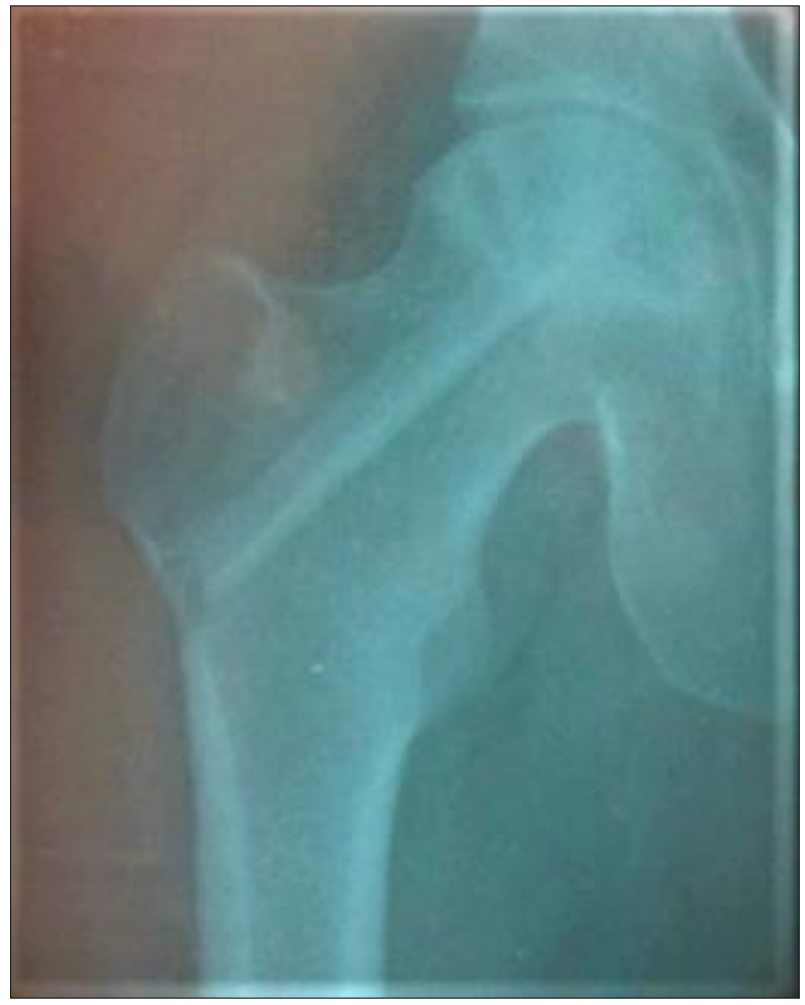

Fig 7: Inserted in to femoral head and neck

We have taken precautionary measure beforehand i.e. we stopped corticosteroid therapy. Follow up was done and suturing site healed and staples were removed on $12^{\text {th }}$ postoperative day but the lesions have increased with great intensity, so we started again low dose steroid therapy. Now patient is symptom free on right hip.

\section{Discussion}

Patients of systemic lupus erythematosus who are treated with steroids have been reported to have a high relative risk of developing avascular necrosis with reported frequency of 5$40 \%$, amongst the non-traumatic causes of avascular necrosis of the femur ${ }^{[12]}$. AVN has long been recognized as a complication of systemic steroid use and was initially believed to occur only in patients who received high doses for extended periods of 3 months or longer ${ }^{[13]}$. The exact mechanism by which steroids cause AVN remains unclear ${ }^{[14]}$. Current research has focused on the development of a hypercoagulable state, with subsequent impaired fibrinolysis and venous thrombosis in bone ${ }^{[15]}$. In addition, steroids cause vasculitis and marked subcortical osteoporosis which further potentiates bone collapse ${ }^{[16]}$.

Anatomical changes of bone collapse and deformity may be seen on plain radiographs, computer tomography (CT) scan and magnetic resonance imaging (MRI) scans, but MRI is the most sensitive modality in the diagnosis of early disease in which plain radiographs and CT may appear normal. Sagittal, coronal and axial MR images allow optimal assessment of the extent of the disease. The vascular response in healing can also be assessed on MRI. Radioisotope bone scan is also useful in early diagnosis and in assessing healing ${ }^{[17]}$.

The treatment of AVN depends on the stage of the disease: core decompression or free vascularised fibular graft in precollapse stage while total hip arthroplasty in post-collapse stage ${ }^{[18]}$.

Clinicians should be aware of complications of steroid therapy. It would be advisable to minimize both the dosage and duration of steroid treatment wherever possible.
Treatment depends upon surgical intervention either femoral head or total hip arthroplasty accordingly.

\section{References}

1. Mendiratta V, Khan A, Solanki RS. Avascular necrosis: A rare complication of steroid therapy for pemphigus. Indian J Dermatol. 2008; 53:28-30.

2. Pietrogrande V, Mastomarino R. Osteopatia da prolungato corticosico. Ortopedia e traumatologia dell' apparatomotore. 1957; 25: 791-810.

3. Richard L Cruess. Montreal. Cortisone induced avascular necrosis of the femoral head. Bone Joint Surgery. 1982; 59-B:308-317.

4. Banks HH. Factors influencing the result in fractures of the femoral neck. J Bone Joint Surg Am. 1962; 44:931.

5. Smith FB. Effects of rotary and valgus malposition on the blood supply to femoral head; observations at arthroplasty. J Bone Joint Surg Am. 1959; 41:800-15.

6. Brav EA. Traumatic dislocation of the hip: Army experience and results over a tweive year period. J Bone Joint Surg Am. 1962; 44:1115.

7. Lowe HG. Avascular necrosis after slipping of the upper femoral epiphysis. J Bone Joint Surg Br. 1961; 43:688.

8. Herndon JH, Autranc OE. Avascular necrosis of the femoral head in the adult. A review of its incidence in a variety of conditions. Clin Orthop Relat Res. 1972; 86:43-62.

9. Bergstein JM, Wiens C, Fish AJ, Veinier RL, Michael A. Avascular necrosis of bone in systemic lupus erythematosus. J Pediatr. 1974; 85:31-5.

10. Hickmann JG, Tindall JP, McCollum DE. Aseptic (avascular) necrosis of the femoral head in psoriasis. South Med J. 1979; 72:121-3.

11. Wang G J, Sweet D E, Reger SI, et al.Fat cell changes as a mechanism of avascular necrosis. J Bone Joint Surgery. 1982; 64-A; 1:139-141.

12. Shim SS, Hawk HE, Yu WY. The relationship between blood flow and cavity pressure of bone. Surg Gynaecol Obstet. 1972; 135:353-60.

13. Haajaen J, Saarinen O, Laasonen L, Kuhlback B, Edgren J, Slatis P. Steroid treatment and aseptic necrosis of the femoral head in renal transplant receipients. Transplant Proc. $1984 ; 16: 1316-9$.

14. McCluskey J, Gutteridge DH. Avascular necrosis of bone after high doses of dexamethasone during neurosurgery. Br Med J (Clin Res Ed). 1982; 284:333-4.

15. Glueck CJ, Frieberg R, Glueck HI, Tracy T, Stroop D, Wang Y. Idiopathic osteonecrosis, hypofibrinolysis, high plasminogen activator inhibitor, high lipoprotein (a) and therapy with stanozol. Am J Hematol. 1995; 48:213-20.

16. Wong GK, Poon WS, Chiu KH. Steroid-induced avascular necrosis of the hip in neurosurgical patients: Epidemiological study. ANZ J Surg. 2005; 75:409-10.

17. Dion E, DeGennes C, Attias S, Zaimm S, Auberton E, Grellet J. Asymptomatic avascular necrosis of the femoral head: Prevalance in systemic lupus erythematosus. Radiology. 1994; 193:150.

18. Louie BE, McKee MD, Richards RR, Mahoney JL, Waddel JP, Beaton DE et al. Treatment of osteonecrosis of the femoral head by free vascularised fibular grafting: An analysis of surgical outcome and patient health status, Can J Surg. 1999; 42:274-83. 